\title{
Prevención de las Fracturas de Cadera en ancianos con el uso de un protector
}

Prevention of hip fracture in elderly people with use of a hip protector. Kannus P, Parkkari J, Niemi S et al. N Eng J Med. 2000; 343:15061513.

\section{Objetivo}

Evaluar la efectividad clínica de los protectores de cadera, en una población de ancianos, de 70 años o mayores, con al menos un factor de riesgo para caídas.

\section{Diseño}

Estudio clínico aleatorizado, multicéntrico, con un seguimiento de 18 meses.

\section{Lugar}

Estudio realizado en 22 centros comunitarios de salud distribuidos en el Sur y Centro de Finlandia.

\section{Pacientes}

Se aleatorizó a 1801 ancianos frágiles ambulatorios, de 82 años de edad promedio (1409 mujeres y 392 hombres), en un factor $1: 2$ (por cada paciente asignado a protector dos no lo estaban). Los criterios de inclusión fueron 70 o más años, y al menos 1 factor de riesgo para fractura de cadera (Caída o fractura previa, deterioro del equilibrio o la movilidad corporal, uso de bastón o andador, deterioro cognitivo o visual, malnutrición, o una enfermedad o droga conocida como predisponente para caídas en ancianos).

\section{Intervención}

Se aleatorizó a los pacientes para usar protectores de cadera $(\mathrm{KPH}$ Hip Protector, Respecta, Helsinki, Finlandia) o no usarlo, durante todo el día mientras estuvieran de pie.

\section{Medición de resultados principales}

La variable principal medida fue la fractura de la cadera (Fémur proximal). Se midieron además otras fracturas, el número y frecuencia de caídas en el grupo de protector, y el número de días que éstos sujetos usaron el protector constantemente.

\section{Resultados}

Durante el seguimiento 13 sujetos sufrieron fracturas de cadera en el grupo protector (21.3 por 100 personas/año) y 67 en el grupo control (46.0 por 100 personas/año). Esto implica un riesgo relativo en el grupo protector de 0.4 , IC $95 \% 0.2$ a $0.8, p=0.008$ ). El riesgo de fractura pélvica fue levemente menor en el grupo protector, aunque no fue estadísticamente significativa la diferencia (RR 0.4, IC 95\% 0.1 a 1.8, p=0.05). El riesgo de otras fractures fue similar en ambos grupos. En el grupo protector, de 1034 caídas, cuatro sujetos se fracturaron mientras lo utilizaban, mientras que de 370 caídas en donde no se utilizó, se fracturaron nueve sujetos (RR 0.2, IC $95 \% 0.05$ a $0.5, p=0.002$ ). El número necesario a tratar (NNT) para prevenir una fractura de cadera al año es de 41 (IC95\% 25:a 115), y a los cinco años el NNT es de 8 (IC $95 \% 5$ a 23 )

La tasa de no aceptación y exclusión de este estudio antes de aceptar los posibles tratamientos fue alta $-31 \%$ y $9 \%$ en el grupo intervención, y el grupo control, respectivamente. Además, la adherencia con el protector en el grupo intervención fue de un $50 \%$.

\section{Conclusiones \\ Los ancianos frágiles, que son susceptibles a sufrir caídas y frac- turas de cadera, fueron beneficiados por el uso de protectores ex- ternos pelvianos. Si el protector fue usado en el momento del even- to traumático, la tasa de fractura de cadera se redujo a $80 \%$.}

\section{Comentario}

La teoría de reducción o gravedad del impacto en la cadera durante una caída es conocida desde hace 40 años. Se decía que los ancianos con poco panículo adiposo en la región trocantérea estaban más expuestos a eventos mayores. También la recomendación del uso de los protectores de cadera forma parte de la tecnología geriátrica para prevenir fracturas en ancianos frágiles o de alto riesgo desde hace aproximadamente dos décadas. De todos modos no había ninguna publicación que avalara el uso de los mismos con adecuada evidencia, contra grupo control, hasta éste trabajo. Si a esto le sumamos que en las últimas décadas de la vida la osteoporosis suma menos riesgo para la fractura de cadera que las caídas, evidenciar un método útil para realizar prevención con bajo costo es alentador. 1-3

La experiencia también indica que a ancianos muy debilitados los programas de rehabilitación con ejercicios del tren inferior no previenen las injurias de manera sustancial, por imposibilidad de los mismos de poder adaptarse al entrenamiento, o por incapacidad del tratamiento de aumentar la masa muscular anti-gravitatoria. 4-5

En vista de los resultados positivos de éste estudio, la intervención parece ser efectiva, y posiblemente costo-efectiva. Estas aumentan si se seleccionan grupos de alto riesgo que usen adecuadamente los protectores de cadera. De todos modos es importante tener en cuenta que en este estudio muchos ancianos no aceptaron usar el protector, y muchos abandonaron el estudio luego de aceptar inicialmente usarlo. Lo que sí parece claro es que los perseverantes obtienen su recompensa.

\section{Dr. Ricardo Jauregui [ Unidad de Medicina Familiar y Preventiva. Hospital Italiano de Buenos Aires ]}

\section{Referencias}

1. Downton JH. Falls in the elderly. London: Edward Arnold, 1993

2. Reuben, D. editor. Geriatrics review syllabus: a core curriculum in geriatric medicine, 1996 program. New York, (NY): American Geriatrics Society, c1996.

3. L. Rubenstein, Approaching falls in older persons, Ann Long Term Care, vol. 8, No. 8, Aug 2000, 61-64

4. Close J, Ellis M. Hooper R, et. al. Prevention of falls in the elderly trial (PROFET): A randomized controlled trial. Lancet 1999: $353: 93-97$.

5. Province MA, Hadley EC, Hornbrook MC, et. al. The effects of exercise on falls: A preplanned meta-analysis of the FICSIT Trials. JAMA 1995; 273(13): 1341-1347. 